\title{
Subcutaneous Implantable Cardioverter Defibrillator Explantation - A Single Tertiary Center Experience
}

\author{
Naga Venkata Pothineni ${ }^{1}$, Tharian Cherian ${ }^{2}$, Neel Patel $^{2}$, Jeffrey Smietana ${ }^{2}$, David \\ Frankel $^{3}$, Rajat Deo ${ }^{1}$, Andrew Epstein ${ }^{2}$, Francis Marchlinski ${ }^{3}$, and Robert Schaller ${ }^{2}$ \\ ${ }^{1}$ University of Pennsylvania Perelman School of Medicine \\ ${ }^{2}$ University of Pennsylvania \\ ${ }^{3}$ Hospital of the University of Pennsylvania
}

September 25, 2021

\begin{abstract}
Background: The subcutaneous implantable-cardioverter defibrillator (S-ICD) is an appealing alternative to transvenous ICD systems. However, data on indications for S-ICD explantations are sparse. Objectives: To assess incidence and indications for S-ICD explantation at a large tertiary referral center. Methods: We conducted a retrospective study of all S-ICD explantations performed from 2014 to 2020. Data on demographics, comorbidities, implantation characteristics, and indications for explantation, were collected. Results: A total of 64 patients underwent S-ICD explantation during the study period. During that time, there were 410 S-ICD implantations at our institution of which 53 (12.9\%) were explanted with a mean duration from implant to explant of $19.7 \pm 20.1$ months. The mean age of the patients at explantation was $44.8 \pm 15.3$ years, and $42 \%$ ( $\mathrm{n}=27$ ) were female. The indication for S-ICD implantation was primary prevention in $58 \%$ and secondary prevention in $42 \%$ of the patients. The most common reason for explantation was infection (32.8\%) followed by abnormal sensing (25\%) and need for pacing $(18.8 \%)$. Those who underwent S-ICD explantation for pacing indications were significantly older ( $55.7 \pm 13.6$ vs $42.3 \pm$ 14.6 years, $\mathrm{p}=0.005)$ with a wider QRS duration $(111 \pm 19 \mathrm{~ms}$ vs $98 \pm 19 \mathrm{~ms}, \mathrm{p}=0.03)$ at device implantation compared to patients who underwent explantation for other indications. Conclusion: Incidence of S-ICD explantation in a large tertiary practice was $12.9 \%$. While infection was the indication for a third of the explantations, a significant number were due to sensing abnormalities and need for pacing. These data may have implications for patient selection for S-ICD implantation.
\end{abstract}

\section{Hosted file}

Manuscript.docx available at https://authorea.com/users/333781/articles/538852-subcutaneousimplantable-cardioverter-defibrillator-explantation-a-single-tertiary-center-experience 


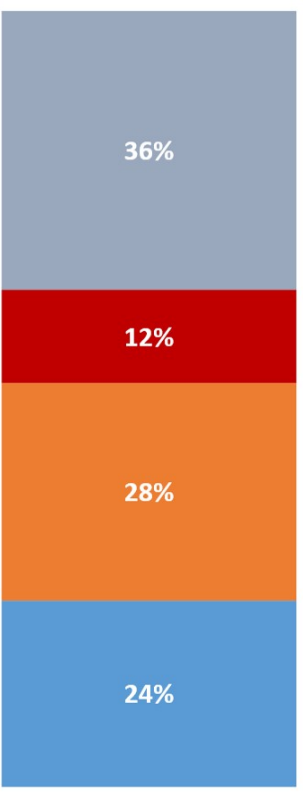

First generation

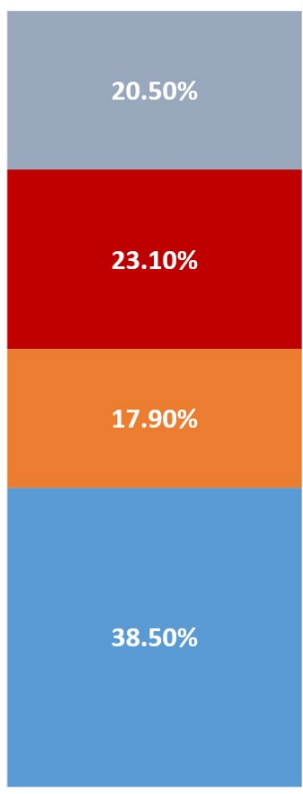

Second generation

Infection Abnormal sensing/inappropriate sensing $\square$ Need for Pacing Other

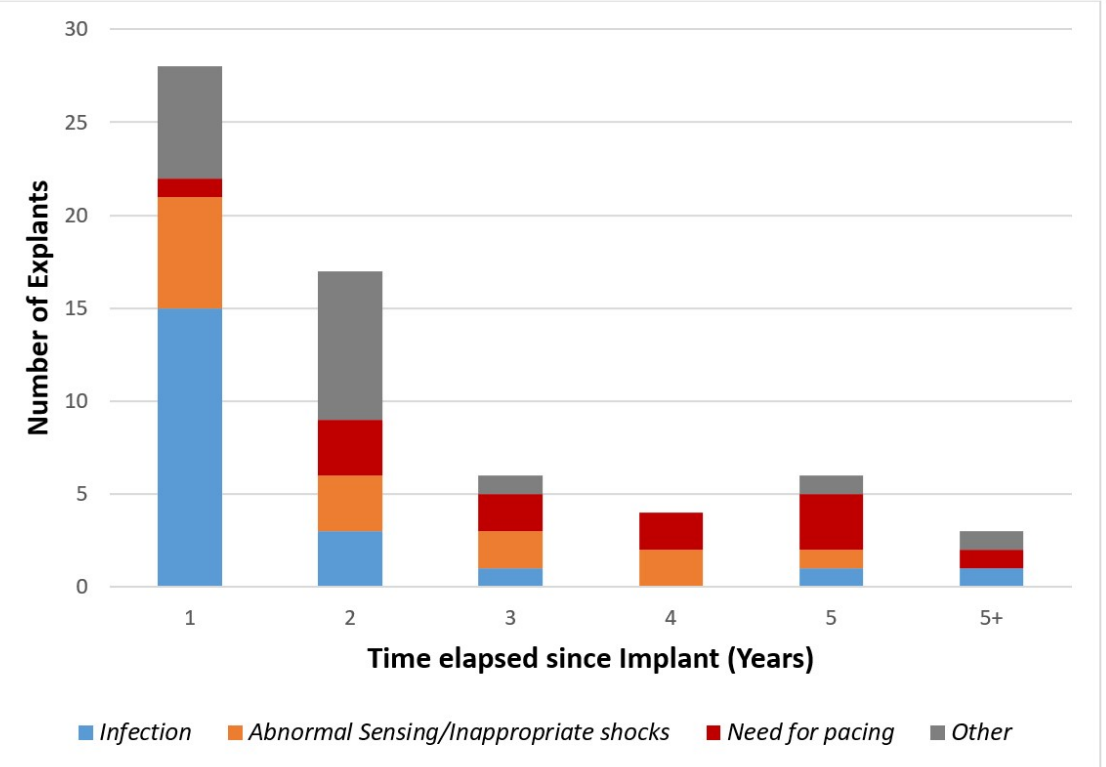

